\title{
CHARACTER BELIEF AND BEHAVIOUR POTRAYED IN M.NIGHT SHYMALAN'S DEVIL (2010) AS A PSYCHOANALYSIS STUDY
}

\author{
Destha Pratama Putra ${ }^{1}$, Endang Yuliani Rahayu ${ }^{2}$ \\ Faculty of Language and Cultural Studies, Stikubank University \\ e-mail: destaputra50@gmail.com¹ ${ }^{1}$ endangyuliani@edu.unisbank.ac.id ${ }^{2}$
}

\begin{abstract}
This research entitled Character Belief and Behaviour Potrayed in M. Night Shyamalan's Devil (2010) As A Psychoanalysis Study. In this research the researcher analyzes the character belief and behaviour toward superstition in M. Night Shyamalan's Devil (2010). The object used in this research is a film by M. Night Shyamalan entitled Devil In analyzing the data researcher applied a qualitative research. The technique that used to analyze the film is by reading the script and watching the movie and then the researcher applied Carl Gustav Jung's theory of consciousness, namely personal unconscious, collective unconscious, and archetype. Data is collected by watching films and reading dialogue scripts. After analyzing the data it can be concluded that the reason why the character believes in superstition is due to the story of the character's mother and opinions that are repeated over and over. The behavior that is reflected by the character after believing in superstition is the character trying to solve the case using a religious point of view. Meanwhile the effect that arises after believing in superstition is that they succeed in knowing and realizing that the mastermind behind the case is devil.
\end{abstract}

Key Words: Psychoanalysis, Personal Unconscious, Collective Unconscious, Archetype, Superstition

\section{INTRODUCTION}

As human beings we certainly have encountered things that happened outside reason, for example, we felt seeing a sighting that just disappeared, or we have heard something but when we look we don't find the source of the sound, that kind of thing is called superstitious. Superstition is a belief in the supernatural which is to say, a belief in the existence of forces or entities that do not conform to the laws of nature or a scientific understanding of the universe. Superstitions thing are included belief in magic, belief in omens (good or bad), belief in good luck charms and rituals (a lucky penny, throwing salt over one's shoulder to avoid the "bad luck" incurred by spilling same), belief in divination (fortune telling and prophecy), and belief in ghosts or a spirit world beyond what can be explained by science.

For those who believe in superstition, some of them have some underlying causes, such as myths. Myth is a tales believed as true, usually sacred, set in the distant past or other worlds or parts of the world, and with extra-human, inhuman, or heroic characters. Myth can be spread through public spreading or stories from generation to generation from our 
ancestors. The myths that flourished in society sometime will affect the public's own belief in responding to it.

Mythical myths about the existence of ghosts themselves have been growing in society, and even many of them believe it. There are two factors influencing people believe in superstition. First is a curiosity factor, some of us who have a high curiosity about things that we have never seen or felt at first usually will seek a logical explanation or in this case scientifically, even a lot of official research done just to prove the devil existence, for example in April 1998, the Journal of the Society for Psychical Research published a paper entitled The Ghost in the Machine by Coventry University lecturer Vic Tandy. This paper describes Tandy's experiments and experience with infrasound waves while he was working in a medical laboratory.

A lot of researches had been done but many also end up without a satisfying result and this is when the second factor affects them, that is despair. Despair can lead them to inevitably believe in the superstitious because what they think and find out logically does not work then some of them start assuming that if they cannot explain something in natural terms, then it must be something paranormal (Christopher French, Anomalistic Psychology Research, 2000)

The research concerns on the characters of Detective Bowden and Ramirez, who has a different respond to superstitions thing that appear in various scene in the movie. Researchers chose this title because what will be discussed very closely with the culture in Indonesia regarding the many who still believe in superstition things, researchers through the title of this thesis want to explain more clearly about it through the eyes of psychoanalysis.

There are several previous studies regarding archetype analysis, one of which is Situational Archetype Analysis On Demian Karras in William Peter Blatty's The Exorcist written by Imam Setyojati (2015). In his research he analyzed how the influence of situational archetype in building and making the main character Karras become a hero in the story, the author explained in his research that there were several processes in which Karras became a hero who represented part of situational archetype. The first is the Quest which reflects the Quest for the hero, in this phase Karras gets a task to achieve the goal, then there is the Journey which describes the search for evidence of exorcism and demoniac carried out by Karras to convince himself and the church to get permission to do exorcism. The finding of this study are using the situational archetype theory, the researcher can find out the 
development of Demian Karras as a character that reflects the figure of a hero until finally achieving his goal to do exorcism.

Another example of archetypal study was also conducted by Amalia (2014) in her research Archetypal Hero as Reflected in Harry Potter's Character J.K. Rowling's Harry Potter Heptalogy. She analyzes the Harry Potter character that reflects the archetype hero, in her research she explained that like a hero character in the fictional world of Harry Potter it must go through a process and journey that reflects the journey of the situational archetype starting from when he was a child until he reached his goal. In the process of being a hero, there are also several tasks that must be completed, such as looking for Voldemort's Hucrux to kill him. The task also guides Harry Potter to confront his enemy, Voldemort, which reflects the battle between good versus evil. In his journey to become a hero of Harry Potter, he also experienced suffering which reflected the unhealable wound. In her research the researcher can find out the development of Harry Potter's character in his efforts to defeat his enemy.

After reading the two studies, the researcher compared them to the research conducted by the researcher, there were differences between them, the two studies focused more on the archetypal situational which was reflected by the hero characters in the two products of the fiction literature, while the research conducted by researchers discussed more generally the behavior and beliefs of the main characters in the devil 2010 film, using Jung's three consciousness theories namely personal unconscious, collective unconscious, and archetypes.

\section{LITERATURE REVIEW}

Jung strongly emphasized that the most important part of a person's unconscious labyrinth is not from personal experience, but it is from human existence in the past. This concept is what Jung called collective unconscious. An important point of Jung's theory is personal unconsciousness. Here are three levels of consciousness according to Jung.

\subsection{Conscious Realm}

According to Jung, the reflection about the conscious is something that can be felt by the ego, while the unconscious element has nothing to do with the ego. Jung's beliefs that the ego are stricter than Freud's view. 
Jung saw the ego as the centre of the field of consciousness which contains our conscious awareness of existing and a continuing sense of personal identity. It is the organizer of our thoughts and intuitions, feelings, and sensations, and has access to memories which are not repressed. The ego is the bearer of personality and stands at the junction between the inner and outer worlds. [Ann Hopwood: 2017: 1]. However ego is not the core of conscious itself. Ego is not the whole of personality and must be fulfilled with self. This self is the center of most personalities, including unconscious. In psychology of healthy people, the ego is the second aspect of the unconscious. It makes conscious plays a relatively small role in analytical psychology.

\subsection{Personal Unconscious}

Personal unconscious refers to all information and experiences that are forgotten, suppressed, and sublimated This is as stated in the following:

The personal unconscious contains of past memories and impulses, forgotten events, and various experiences stored in the unconscious. Our personal unconscious is shaped by individual experience [1].

The picture of the personal unconscious can be remembered easily or difficult, but there are also some parts that are far from the reach of human consciousness. The contents of this personal unconscious are called the Complex. A complex is an accumulation of a collection of ideas colored by feelings. Complex in general can be categorized as something personal, but complex can also be derived from the collective experience of one's humanity.

\subsection{Collective Unconscious}

Based on Jung's concept the physical content that accompanies collective consciousness is inherited from one generation to the next as a potential psychological condition. This is as found in the following:

People are in a condition and time that is influenced by the primordial experience of primitive ancestors Thus, the contents of the collective unconscious are more or less the same in all cultures in the world [2].

The collective unconscious does not refer to an inherited idea, but rather to the strong tendency of humans to react in certain ways when their experiences simulate biologically derived tendencies. Humans, like animals, come to this world with predetermined inheritance to be able to react and react in certain ways if their experiences touch their biological side. Jung said that a man's collective unconscious that contains biological impressions on a woman then plays a role when he sees the woman he loves. This is in line with the following: 
Jung said that humans have inherited tendencies and their numbers are the same as typical situations in human life. [3]

It means that repetition of an infinite number of typical situations will make it part of the human iological constitution.

\subsection{Archetypes}

Archetypes are images of the past and even archives that originate from the collective unconscious. Archetype is also a form of mind that has a large emotional load that represents or symbolizes the chance of certain types of perception and action.

Archetypes are more common and originate from the collective unconscious content. Archetypes must be distinguished from instincts. [4].

Jung defines instincts as a physical unconscious impulse for action, whereas he sees archetypes as a rival instinct because they are psychic. Both archetypes and instincts are unconscious and both can help forming personality. Archetypes do have a biological basis, but they are rooted through the experiences of human ancestors, which are repeated throughout the generations.

In the process of its appearance, archetype takes many form to represent its type, it can be in the form of fantasy or dream, such as a statement in one of the Jung's book.

Archetypes themselves cannot be directly represented but when activated they express themselves through several modes, mainly through dreams, fantasies, and delusions [4].

An explanation of the archetype appearance can also be found through Jung's explanation about his dreams and fantasies in his biography. During his mid-life struggle with his unconscious, Jung had many of these archetypal dreams and fantasies. Jung often begins fantasies by imagining that he is being sent down to a deep cosmic abyss. He was only able to understand a few of his visions and dreams at the time, however, the next time he began to understand that dream images and fantasy figures were basically archetypes, the experiences produced an entirely new meaning. This is as stated in following

Dreams are the main source of archetypal material, and certain dreams offer what Jung considers evidence of the existence of archetypes. Jung believes that hallucinations of psychotic patients also offer evidence for these universal archetypes [5].

It also can be concluded that the appearance of dreams and hallucinatory experience are the source of the archetype material itself. 
Just like Jung, Freud also believes that humans collectively inherit tendencies to act. However, the concept of phylogenetic innate is somewhat different from Jung's formulation. One difference is that Freud focused more on the personal unconscious, and put innate phylogenetic it is only if this personal explanation fails - as he sometimes does when describing the Oedipus complex. In contrast, Jung emphasizes the collective unconscious and uses personal experiences to strengthen the total personality. But the main difference between the two is that Jung placed the collective unconscious as autonomous forces, which he called archetypes, each of which had its own life and personality. The most biased types of this type include persona, shadow, anima, animus, great mother, wise old man, hero, and self. The following are types of archetypes, and explanations of each type.

\section{RESEARCH METHOD}

In analyzing this movie the researcher uses qualitative approach in analyzing the researcher tries to interpret the data to be analyzed as told by Denzin and Lincoln (1994:2) Qualitative research is multi method in focus, involving an interpretive, naturalistic approach to its subject matter. The technique that will be used to analyze the film is by reading the script and watching the movie and then the researcher will apply Carl Gustav Jung's theory of consciousness namely personal unconscious, collective unconscious, and archetype. The object used in this research is a film by M. Night Shyamalan entitled Devil.

\section{FINDINGS AND DISCUSSION}

This is the result of data analysis that cover the causes why the characters believe in superstition, describe their action in believing in superstition, and the effect of believing in superstition. In the Devil (2010) by M. Night Shyamalan. It focuses on the two main character in this movie regarding how they response in superstition.

\subsection{Character believe in superstition}

In the devil movie there are two main characters that have different perspectives in superstitious things. The first is Ramirez, he works in one of the office buildings as one of the security. Ramirez's life since childhood was full of religious things which made him grow up to be someone close to a very thick religious culture. Ramirez's belief in superstitious things stems from his mother's story when he was a child, this story is about devils who can take 
human form and roam to punish the damned people on earth. This is as found in following quotation

"When I was a child, my mother would tell me a story about how the Devil roams the Earth would. She said, he would take the form so he could punish the damned on earth before claiming their souls. The ones he chose would be together and tortured as he hid among them, pretending to be one of them. I always believed my mother was telling mean old wives' tale." (Devil 2010, 01:08 - 01:36)

As found in the narration, one of the characters, Ramirez, stated how he could believe in superstition. Ramirez believes in superstition through his mother's story about the appearance of devil, this belief process is one example of a collective consciousness in the form of past memories possessed by each individual that was passed down through generations, superstitious stories about devils or demons have existed since ancient times and still exist until today because this has been an ancient memory of our ancestors.

\subsection{The action in believing in superstition}

In the process of believing that the case they faced one thing that was reaway the devil in the elevator by kneeling and praying. And this is the prayer as stated below in English quotation:

Hail Mary, full of grace,

The Lord is with thee.

Blessed art thou among women,

And blessed is the fruit of thy womb, Jesus.

Holy Mary, Mother of God,

Pray for us sinners,

Now and at the hour of our death.

Amen

(Devil 2010, 51:44 - 52:01)

What Ramirez does is a form of reaction that came out because of experience related to superstitious things that arise from the collective unconscious, Ramirez's belief about superstitious things that originated from his mother's story also indirectly made him determine the reaction he showed if he experiences something related to his mother's story about devil.

\subsection{The effect in believing superstition}

After the two characters in the movie begin to believe in superstition, there are two different responses in looking at this mysterious case. Ramirez, who is from the beginning had believed in superstition, preferred to surrender and tried to find solutions from the 
spiritual side, such as when he knelt and prayed through the microphone that connected to the elevator to calm the trapped victims and ask for protection.

In addition, Ramirez also often gave his opinion on Bowden about his views on this case. Ramirez tried to convince Bowden with his explanation that Devil was the mastermind of this case and this is as proved in the following:

Ramirez: So today, someone committed suicide, a woman got hurt, now a man is dead.

Bowden: Yeah, what are you trying to say?

Ramirez: Look, how many times have you seen a child fall and barely miss the edge of the table with their head? Why is it so rare that they hit it?

Bowden: Get to your point.

Ramirez: Look. When he's near, everything goes wrong. Toast falls jelly-side down, children hit tables and people get hurt. Sometimes he takes human forms and forms the damned on Earth before stealing them away. Where I come from, we call it The Devil's Meeting.

Bowden: Is this guy for real?

Ramirez: You must consider that one of those people might be the Devil. (Devil 2010, $32: 25-33: 28)$

It is obvious that explanations and opinions about devil that Ramirez often throws at Bowden, also illustrate how this character if we look from the perspective of his archetypical theory, was the only person who from the beginning of this case has believed in superstitious. It is also placing his role as a guide for other characters to solve the case. Characters like this can be categorized as characters that have archetype the sage

As explained by Jung, in general archetype the wise old man / sage is depicted as a person who has a guiding soul who will assist the hero in his journey with all his advice. The character like Ramirez who knows more about devils and superstitious things tries to guide Bowden who is described as a character that reflects the hero in completing his task to save the 5 people trapped in the elevator with the Devil.

Meanwhile on the other hand Bowden's attitude showed a change in responding to his case. The development of Bowden's character in the process of being able to believe in the superstitious can be analyzed from the story's plot in the film. Starting from the beginning of the introduction of Bowden's character who was a detective who was still mourning because he lost his wife and son in the hit and run incident, then he found a case that was quite strange, investigate and rescuing 5 people who were trapped in the elevator, which finally met him with Ramirez the security of the building where the case occurred which always insisted on telling him that the mastermind of this case was a devil, until the climax when he began to believe in superstitious things because of all the Ramirez stories that affected his 
personal consciousness, which made him very curious to find out the solution of the case . This can be seen from some of his dialogue with Ramirez as follows:

Bowden: In a hypothetical conversation that I'm not really having, how would this story of yours end?

Ramirez: They all die. (Devil 2010, 54:10 - 54:19)

Bowden: According to your story, how would I save them?

Ramirez: There's no easy answer. You're never gonna get these people to see themselves as they really are 'cause it's the lies that we tell ourselves, they introduce us to him. (Devil 2010, 01:03:18 01:03:36)

In both dialogues it shows Bowdens openness to the superstition phenomenon in his case. He began to be curious and asks Ramirez about Devils story and how the story ended these questions indicate that Bowden had begun to open his mind about superstition in order to solve the case.

Bowden's journey in solving problems in this devil movie reflects one of the archetypes, the Hero, as explained by Jung in his book Archetypes and the Collective Unconscious this archetype represents the process of overcoming obstacles to achieving specific goals.

\section{CONCLUSION}

Research conducted on the 2010 Devil movie gives us knowledge of the theory of consciousness put forward by Jung. In examining objects, the researcher applies Jung's two theories, namely personal unconscious and collective unconscious along with archetype. By applying these two theories, researchers examined the two characters found in the 2010 Devil movie about how their behavior and beliefs respond to superstitions. After discussing the finding the writer may draw conclusion as follow:

1. The two characters have different ways of believing in superstition. Ramirez, he gained trust in superstition through his mother's story of Devil who was repeatedly told to him when he was a child. This is what made the story eventually become a collective unconscious concept that influenced Ramirez in viewing and responding to the elevator case. Meanwhile the other character that is Bowden, since the beginning he prefers to use logical methods. At first Bowden found him difficult to believe in superstition and devil. Based on the concept of consciousness theory this happened because Bowden still had no experience of superstitious matters. Until Ramirez's story and explanation of devil that acted as complexes finally helps him to gradually begin to believe in superstition. 
2. After believing in superstition they show various actions toward the case, while Ramirez prefers to try to solve the case using a religious perspective by praying, on the other hand Bowden chooses to try to resolve the case by trying to find out more about Devil with Ramirez's favors. Ramirez is reflecting the archetype of the sage who always gave Bowden advice through his opinions and explanations about Devil to solve the case.

3. And then the effect of their belief in superstition is that they can find out the motives and mastermind of the case which turned out be the act of the Devil to bring Bowden together with the mechanic who is the perpetrators of the murder of his wife and son in a hit-and-run incident five years ago to make a judgment.

\section{SUGGESTION}

Based on the findings and discussion the researchers suggest that future researchers if they want to conduct research with the same study and use this study as a comparison, direction or additional reference for their future research. In the future researchers suggest them to be able to analyze more deeply about the theory of consciousness. Moreover, researchers hope that future researchers will be able to focus their analysis on the archetype which is part of the collective unconscious, because this archetype has so many types. In this study researchers only included one type of archetype character, hero. In the future researchers hoped that the next researchers will be able to analyze other archetype categories such as for example situational archetypes, symbols, or plots.

\section{BIBLIOGRAPHY}

Jung, Carl Gustav. 1917. Psychology of The Unconscious. New York: Moffat, Yard and Company.

Jung, Carl Gustav. 1966. Collected Work of C. G. Jung Volume 7: Two Essays in Analytical Psychology, New Jersey: Princeton University Press

Jung, Carl Gustav. 1968. Collected Work of C. G. Jung Volume 12: Psychology and Alchemy, New Jersey: Princeton University Press.

Jung, Carl Gustav. 1980. The Archetypes And The Collective Unconscious. New Jersey: Princeton University Press.

Bair, Deirdre. 2003. Jung: A Biography. New York: Little Brown and Company. 